\title{
Computational Methods Elucidate Consequences of Mutations and Post- Translational Modifications on Troponin I Effective Concentration to Troponin C
}

\section{Supplemental Material}

Austin Cool $^{1}$, Steffen Lindert ${ }^{1, *}$

${ }^{1}$ Department of Chemistry and Biochemistry, The Ohio State University, Columbus, $\mathrm{OH}$

*Correspondence to:

Department of Chemistry and Biochemistry, The Ohio State University

2114 Newman \& Wolfram Laboratory, $100 \mathrm{~W} .18^{\text {th }}$ Avenue, Columbus, OH, 43210

614-292-8284 (office), 614-292-1685 (fax)

lindert.1@osu.edu

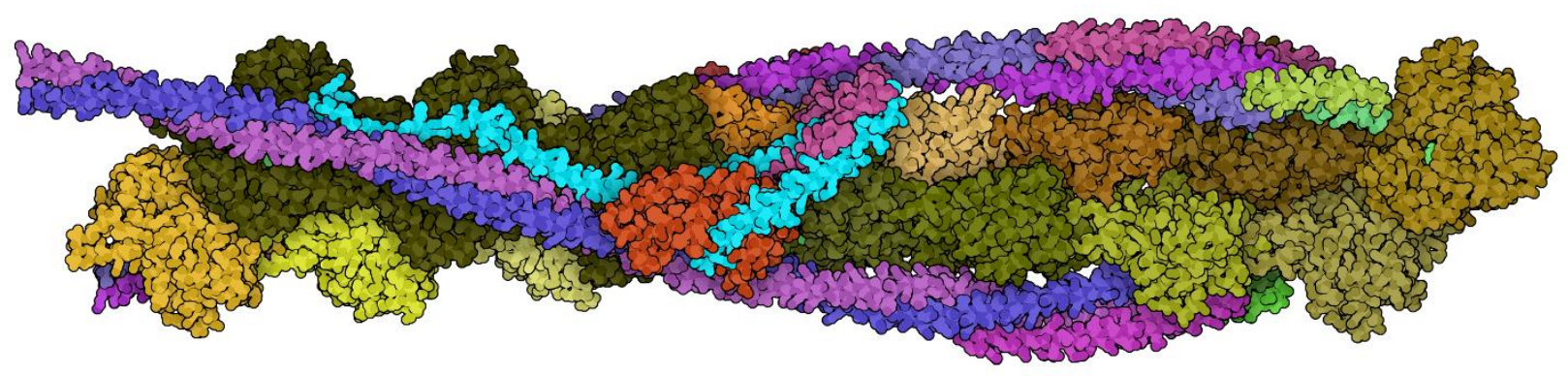

Figure S1. Cartoon representation of the cardiac thin filament. Shown are the actin monomers (green/brown), tropomyosin (pink/purple), cTnC (red), cTnI (light blue), and cTnT (light pink). Graphic was created with the $\mathrm{Ca}^{2+}$ free Yamada et al. model (PDB: 6KN7) using the software Illustrate. The orientation of cTn is reversed from that shown in Figure 1.
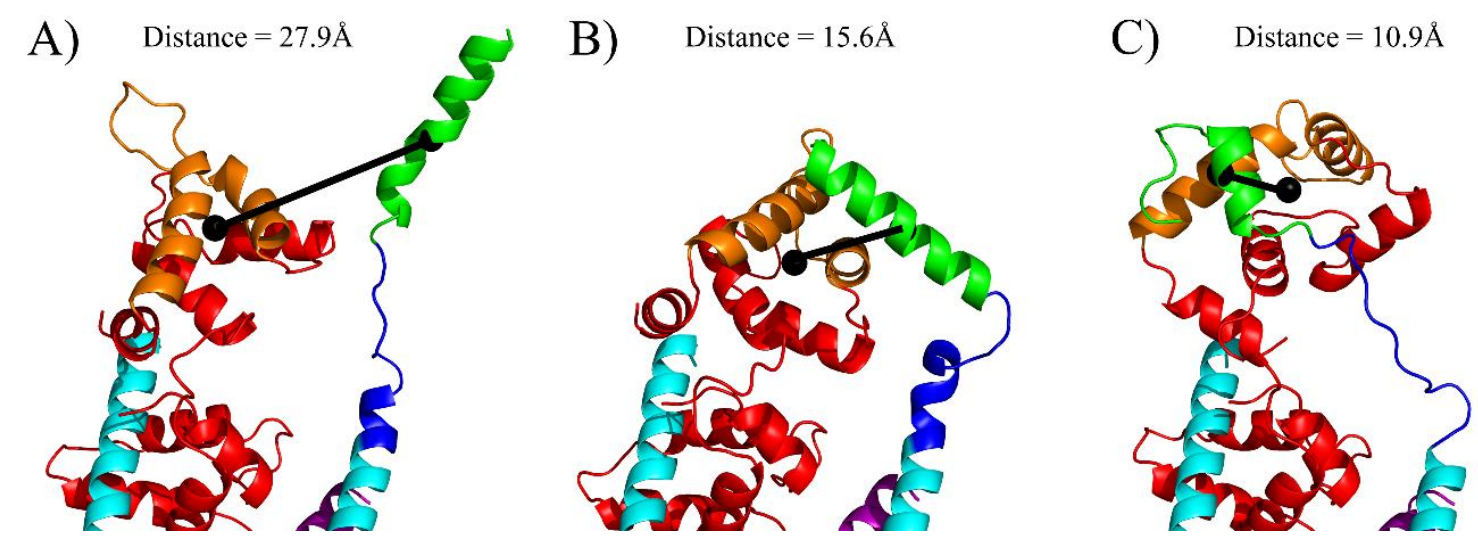

Figure S2. Distance between cTnI ${ }_{s P}$ and $\mathbf{c T n C} \mathbf{C H P}_{\mathrm{HP}}$. Center of $\mathrm{cTnC}_{\mathrm{HP}}$ and $\mathrm{cTnI}_{\mathrm{SP}}$ both shown as black spheres with a line connecting them. A) PDB 6KN7 starting model representing $\mathrm{cTnI}_{\mathrm{SP}}$ not interacting with $\mathrm{cTnC}_{\mathrm{HP}}, \mathrm{B}$ ) representative model of $\mathrm{cTnI}_{\mathrm{SP}}$ interacting with a closed $\mathrm{cTnC}_{\mathrm{HP}}$, and $\mathrm{C}$ ) shows $\mathrm{PDB}$ 6KN8 starting model representing $\mathrm{cTnI}_{\mathrm{SP}}$ interacting with an open $\mathrm{cTnC}_{\mathrm{HP}}$. $\mathrm{cTnT}$ is shown in purple, $\mathrm{cTnC}$ is shown in red, helices that line the $\mathrm{cTnC}_{\mathrm{HP}}$ are shown in orange, the IT arm of $\mathrm{cTnI}$ is shown in cyan, with the $\mathrm{cTnI}_{\mathrm{IP}}$ in dark blue and the 
A)

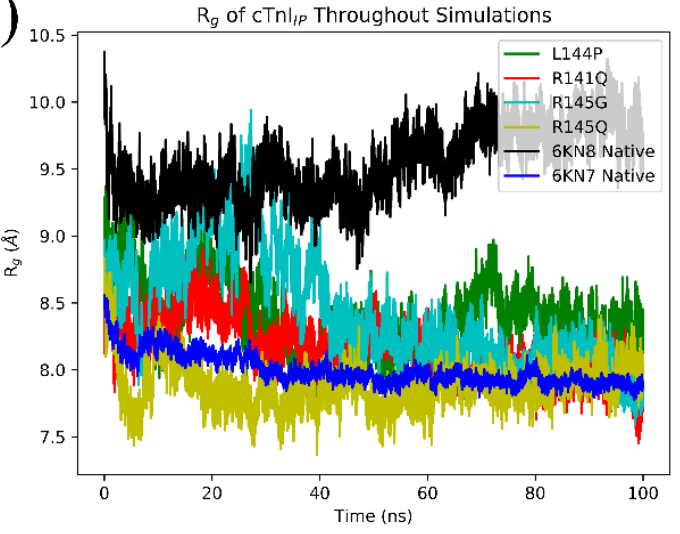

B)

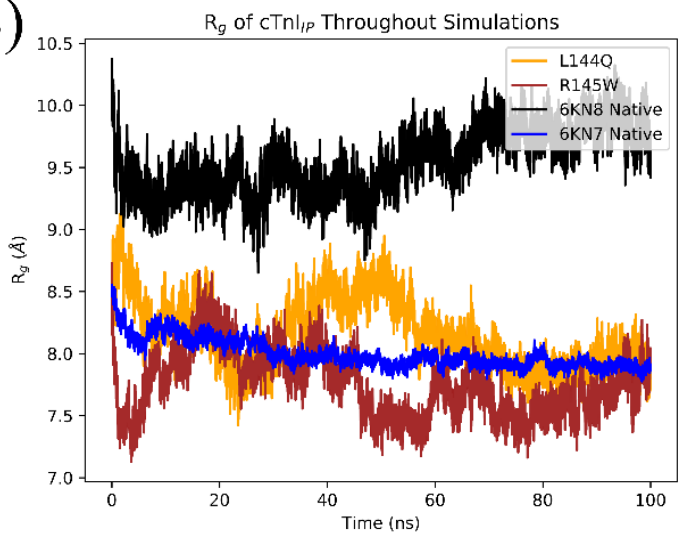

Figure S3. Radius of gyration $\left(\mathrm{R}_{\mathrm{g}}\right)$ of the cTnlip region (residues 137-148). A) Data for four HCM mutations and B) Data for two RCM mutations. Both graphs contain the $6 \mathrm{KN} 7$ and $6 \mathrm{KN} 8$ native data.

A)

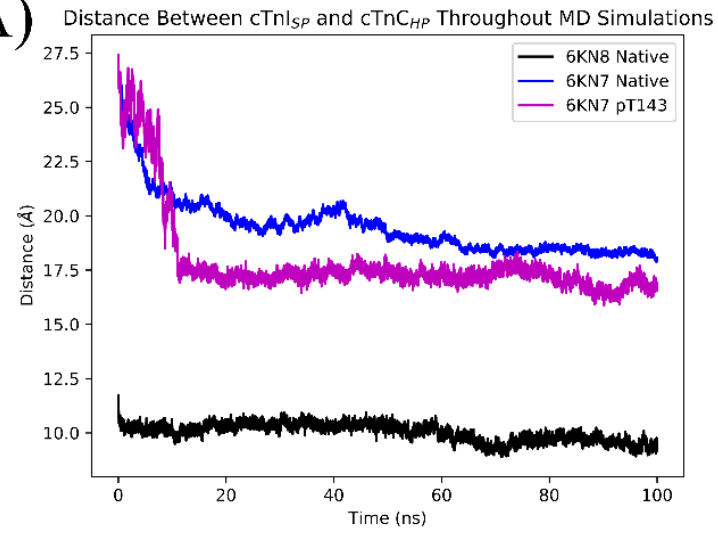

B)

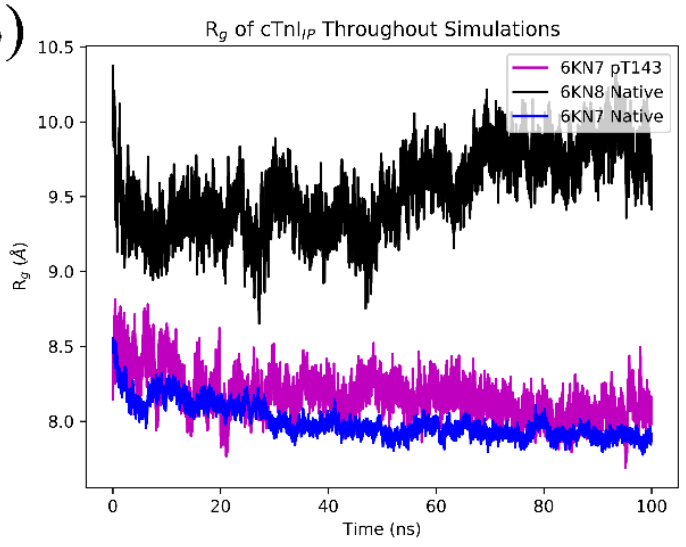

Figure S4. A) Distance between $\mathrm{cTnI}_{\mathrm{SP}}$ and $\mathrm{cTnC}_{\mathrm{HP}}$ and B) $\mathrm{R}_{\mathrm{g}}$ for the $\mathrm{pT} 143$ models throughout the simulations.

A)

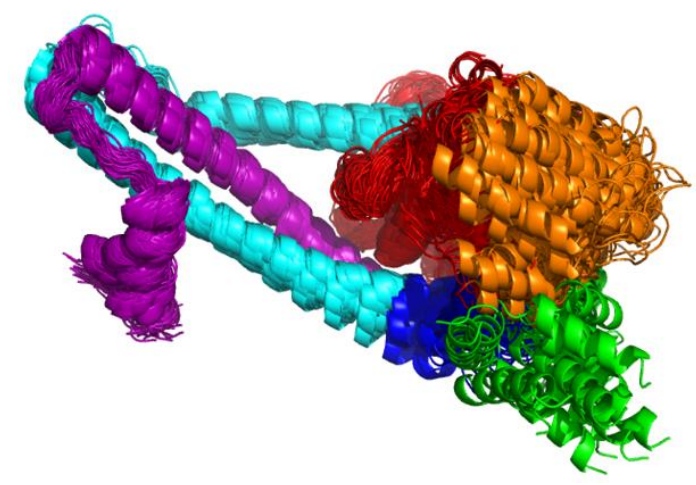

B)

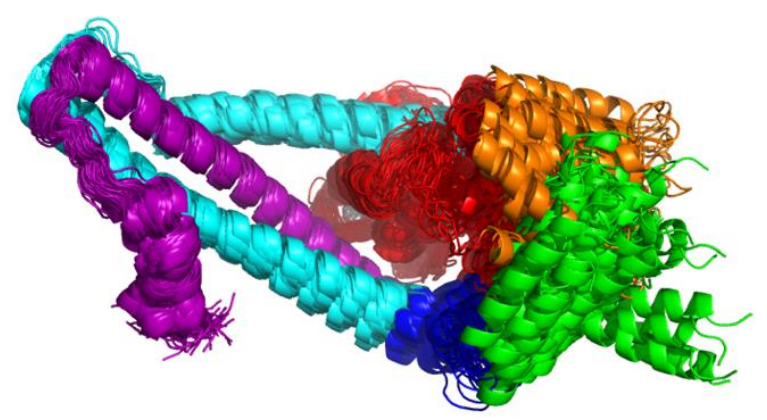

Figure S5. Ribbon representations of conformations sampled by troponin. A) native and B) pT143 simulations are shown. Both originated from the same starting structure of $\mathrm{Ca}^{2+}$ bound, cTnI IP tethered, cTnISP unbound. Frames were extracted every $1 \mathrm{~ns}$ to create both figures. cTnT is shown in purple, cTnC is shown in red, helices that line the $\mathrm{cTnC}_{\mathrm{HP}}$ are shown in orange, the IT arm of $\mathrm{cTnI}$ is shown in cyan, with the cTnI $\mathrm{IP}_{\mathrm{IP}}$ dark blue and the cTnI $\mathrm{sP}_{\mathrm{s}}$ in green. 